\title{
The MTHFR C677T variant is associated with responsiveness to disulfiram treatment for cocaine dependency
}

\author{
Catherine J. Spellicy ${ }^{1}{ }^{*}$, Thomas R. Kosten ${ }^{1}$, Sara C. Hamon ${ }^{2}$, Mark J. Harding ${ }^{1}$ and David A. Nielsen ${ }^{1}$ \\ ${ }^{1}$ Menninger Department of Psychiatry and Behavioral Sciences, Baylor College of Medicine and Michael E. DeBakey V. A. Medical Center, Houston, TX, USA \\ ${ }^{2}$ Laboratory of Statistical Genetics, The Rockefeller University, New York, NY, USA
}

\section{Edited by:}

F. Gerard Moeller, University of Texas Health Science Center at Houston, USA

\section{Reviewed by:}

Shaolin Wang, University of Virginia, USA

Keith Heinzerling, University of California, Los Angeles, USA

\section{*Correspondence:}

Catherine J. Spellicy,

Michael E. DeBakey V. A. Medical Center, 2002 Holcombe Blvd.

Research 151, Bldg 109, Rm 129,

Houston, TX 77030, USA

e-mail: spellicy@bcm.edu
Objective: Disulfiram is a one of the few pharmacotherapies for cocaine addiction that shows promise. Since disulfiram and cocaine both affect levels of global methylation we hypothesized the MTHFR gene, whose product is involved in supplying methyl groups for DNA and protein methylation, may be associated with responsiveness to disulfiram in cocaine-dependent individuals. Methods: Sixty-seven cocaine-dependent patients were stabilized on methadone for 2 weeks and then randomized into disulfiram $(250 \mathrm{mg} /$ day, $N=32$ ) and placebo groups ( $N=35$ ) for 10 weeks. Patients were genotyped for the MTHFR (rs1801133, also known as C677T) polymorphism and the data was evaluated for association with cocaine-free urines in the disulfiram or placebo groups. Data from patients that completed all 10 weeks of the study $(N=56)$ were analyzed using repeated measures analysis of variance (ANOVA), corrected for population structure. Results: The CT or TT MTHFR genotype group ( $N=32$ ) dropped from 73 to $52 \%$ cocaine-positive urines on disulfiram $(p=0.0001)$, while the placebo group showed no treatment effect. The CC MTHFR genotype group $(N=24)$ showed a smaller, but still significant, reduction in cocaine-positive urines on disulfiram compared to placebo; $81-69 \%(p=0.007)$. Conclusion: This study indicates that a patient's MTHFR genotype may be used to identify individuals who might show improved response to disulfiram treatment for cocaine dependence. Clinical Trial: Pharmacogenetics of Disulfiram for Cocaine, clinicaltrials.gov/ct2/show/NCT00149630, NIDA-18197-2, NCT00149630.

Keywords: genes, disulfiram, polymorphism, cocaine, treatment, dependence

\section{INTRODUCTION}

Substance abuse is a critical problem in the United States. Cocaine is one of the most common drugs of abuse and the effects of cocaine dependency $(\mathrm{CD})$ lead to social and physiological morbidities. Drug abuse and drug addiction costs employers over 122 billion dollars in lost productivity and time, and another 15 billion dollars in health insurance costs each year [Substance Abuse and Mental Health Services Administration (SAMHSA), 2011] indicating that substance abuse and addiction have significant economic impact. CD also may lead to risky behaviors making HIV, illicit opioid use, and emergency care more common [Substance Abuse and Mental Health Services Administration (SAMHSA), 2011].

Although CD is currently without an FDA-approved pharmacotherapy, some drugs show promise in treatment of $\mathrm{CD}$, an example of which is disulfiram (Carroll, 1993; Carroll et al., 1998, 2004; George et al., 2000; Petrakis et al., 2000). Disulfiram, also known as Antabuse, is used to treat alcoholism via its blockage of the conversion of acetaldehyde (a metabolite of ethanol) into acetic acid, thereby inducing aversive physiological symptoms such as nausea and vomiting. The exact mechanism by which disulfiram exerts its effect to reduce cocaine cravings and/or use is not exactly known. However, studies have shown that genetic background may be important in determining responsiveness to disulfiram as a $\mathrm{CD}$ pharmacotherapy (Kosten et al., 2012).

$\mathrm{CD}$ is a complex disease with a strong genetic component as indicated by a heritability of up to $72 \%$ (Tsuang et al., 1998; Goldman et al., 2005) and increased odds ratios up to 40.8 in monozygotic twins as compared to dizygotic twins (Kendler and Prescott, 1998). Studies have shown that individual genetic variants are associated with risk of substance abuse, including $\mathrm{CD}$ [but usually only in select populations, e.g., OPRM1 (Berrettini et al., 1997), Homer1 (Dahl et al., 2005), OPRD1 (Kreek et al., 2005; Crist et al., 2012)] but also that epigenetics may play a significant role in the disease process (e.g., Nielsen et al., 2009, 2010). Changes in epigenetics, including chromatin structure and DNA methylation, due to drug use, and the resulting change in gene expression are hypothesized to contribute to the neural plasticity in drug users that has long been considered a molecular mechanism through which drug addiction and relapse may occur (e.g., Berke et al., 1998; Nestler, 2001; Grimm et al., 2003; Yao et al., 2004; Shaham and Hope, 2005; Kalivas and O'Brien, 2008; Wong et al., 2011). Cocaine itself is known to affect gene expression via regulating heterochromatin (Maze et al., 2011) and other epigenetic factors (Nielsen et al., 2012b). 
Disulfiram, although not a drug of abuse, also falls into this category of pharmacotherapies that may modify the epigenetic landscape. Disulfiram causes hypomethylation in tumor cell lines via its inhibition of DNA methyltransferase 1 (DNMT1; Lin et al., 2011). DNMT1 is an enzyme involved in maintenance of DNA methylation patterns following mitosis (Kinney and Pradhan, 2011).

In this study, we chose to examine the relationship between response to disulfiram (in terms of cocaine-positive urines over time) and a single nucleotide polymorphism (SNP, rs1801133, also known as C677T) in the gene coding for 5,10-methylene tetrahydrofolate reductase (MTHFR), whose product is central to the folic acid metabolic cycle (see Figure 1). The folate cycle is critical to normal cellular function via supplying metabolites used

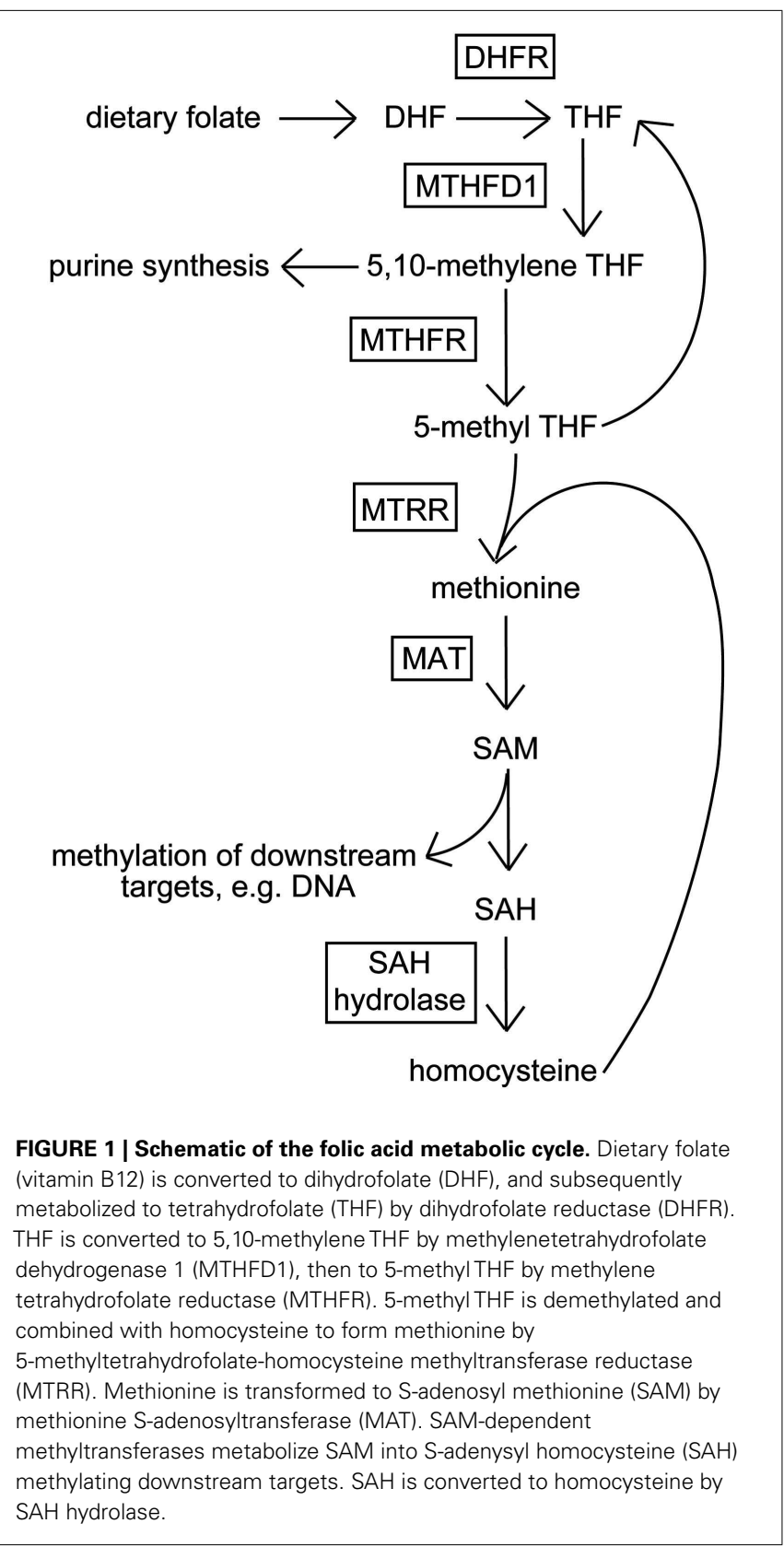

for nucleotide and amino acid synthesis, and for methylation of downstream DNA and proteins. The minor T allele of rs1801133 codes for an amino acid change that leads to a more thermolabile enzyme in vitro (Frosst et al., 1995), and has also been found to associate with neural tube defects (NTDS) such as spina bifida, a condition in which the neural tube, the precursor to the central nervous system (CNS) during embryonic development, fails to close completely leaving neural tissue open to the environment (Whitehead et al., 1995; Harisha et al., 2010).

Given its involvement in both development and function of the CNS, and its importance in biochemical pathways, such as nucleotide synthesis and methylation, we hypothesized that variants in MTHFR may be associated with response to disulfiram treatment in cocaine-dependent individuals.

\section{MATERIALS AND METHODS PARTICIPANTS}

Ninety-three cocaine- and opioid co-dependent patients were enrolled, consented, and stabilized on methadone treatment during a 2-week screening period at Yale University $(N=40)$ and Baylor College of Medicine $(N=53)$. The final number of patients with at least one cocaine-positive urine sample, and that were able to be genotyped, was 67 . Opioid and/or cocaine dependence was diagnosed via interview and the DSM-IV criteria. The MINI (English Version 5.0.0, July 1, 2006; Sheehan et al., 1998) and the ASI (McLellan et al., 1992) were performed on all participants to obtain baseline psychiatric characteristics. Patients were excluded based on current diagnosis of other drug or alcohol dependence (excluding tobacco), current major medical illness not stabilized on medications, a history of major psychiatric disorder (psychosis, schizophrenia, bipolar), current suicidality, or an inability to read and understand the consent form. Women of childbearing age required a negative urine pregnancy test, use of adequate contraception to prevent pregnancy during the study, and monthly pregnancy tests. All participants signed an informed consent approved by Yale University and the Baylor College of Medicine Institutional Review Boards that gave specific consent for genetic studies. Determination of ethnicity was based on self-report of ethnic/cultural background of the patients.

This was a 12 week study in which individuals were assigned randomly to placebo or disulfiram groups ( $250 \mathrm{mg}$ daily). Methadone dose increased $5 \mathrm{mg}$ /day from an initial $25 \mathrm{mg}$ to a maintenance dose of $60 \mathrm{mg} /$ day. Individual cognitive behavioral therapy was provided weekly to all patients (Carroll, 1997).

Supervised urine samples were obtained three times weekly and tested for the presence of a cocaine metabolite, benzoylecgonine, using an Olympus AU 640 Emit system (Olympus America Inc., Melville, NY, USA). The threshold for a positive urine concentration was $300 \mathrm{ng} / \mathrm{mL}$. Saliva samples were collected for genotyping.

\section{GENOTYPING}

DNAs were purified and genotyped as previously described (Kosten et al., 2012). Briefly, $10 \mathrm{~mL}$ Scope mouthwash was used to rinse the subject's mouth for $60 \mathrm{~s}$ and centrifuged to obtain buccal cells. The Gentra Puregene Buccal Cell Kit (Qiagen, Valencia, CA, USA) was used to purify the DNAs following the manufacturer's recommendations. 
The MTHFR C/T rs1801133 genetic variant was genotyped using the TaqMan ${ }^{\circledR}$ (Applied Biosystems, Foster City, CA, USA) primer-probe set (Assay ID C_1202883_20). PCR amplifications were performed using Platinum ${ }^{\circledR}$ quantitative PCR SuperMixUDG (Invitrogen, Carlsbad, CA, USA) on a GeneAmp ${ }^{\circledR}$ PCR system 9700 and read on an ABI Prism 7900 detection system. SDS 2.2 software (Applied Biosystems, Foster City CA, USA) was used to analyze the results. Sex was determined via the presence of a sex-specific variant, rs11575897 in the SRY gene (C_32310143_10, Applied Biosystems). Ten ancestry-informative markers were evaluated to determine ethnicity (Lao et al., 2006). All genotyping experiments were performed in duplicate.

\section{STATISTICAL ANALYSIS}

Statistical analysis was performed as previously described (Kosten et al., 2012). Demographic data was analyzed using chi-squared or $t$-test. R version 2.9.1 (R Development Core Team, 2009) was used to perform a repeated measures analysis of variance (ANOVA) on the cocaine-positive urine data over time in the placebo/disulfiram groups, and by MTHFR genotype. We performed statistical comparisons between conditions (disulfiram or placebo), MTHFR genotypes $(0=\mathrm{CC}$ genotype, $1=$ all other genotypes), time (each 2 week period), and then examined potential interactions between condition and time, and/or between condition and genotype. We analyzed those individuals who had complete urine toxicology data $(N=56)$, and as a secondary analysis, included those individuals with incomplete urine toxicology data $(N=67)$. We calculated effect size as a partial eta-squared statistic using condition or SNP variance over residual variance. The three general cutoffs for effect size are the following: a small effect is 0.01 , medium effect is 0.06 , and large effect is 0.14 .

To determine population structure, our cohort was compared against Centre d'Etude du Polymorphisme Humain - Human Genome Diversity Project (CEPH-HGDP) samples (1,035 subjects of 51 populations; Kosten et al., 2012) using the STRUCTURE 2.3.3 software (Pritchard et al., 2000; Hubisz et al., 2009).

\section{RESULTS}

\section{BASELINE CHARACTERISTICS BY TREATMENT AND MTHFR GENETICS}

Sixty-seven patients, 32 that had been randomized to disulfiram treatment group and 35 to placebo group, were genotyped. The patients with complete urine toxicology data for the 12 weeks of the trial included 32 individuals with a CT or TT genotype and 24 individuals with a CC genotype. The patients had a mean age of 38 years and were mostly Caucasian $(76 \%)$ and mostly male (71\%). Twenty-eight (50\%) patients had previously been in a methadone maintenance treatment program. On average, participants used cocaine for 12 years and for 17 days in the month prior to entering this study (see Table 1). An additional 11 patients were genotyped that had an incomplete urine toxicology and for whom demographic data is not shown.

Twenty-eight patients (50\%) reported any alcohol use history ( $>1$ year), and 21 patients $(37.5 \%)$ reported marijuana use history. We found no significant baseline differences among the four treatment by genotype groups in any clinical characteristics except for cocaine use in years ("cocaine years"), but this became non-significant after adjusting for multiple testing $(p>0.05)$.
Table 1 | Clinical and demographic characterization by treatment and genotype.

\begin{tabular}{|c|c|c|c|c|}
\hline \multirow{3}{*}{ MTHFR genotype } & \multicolumn{4}{|c|}{ Treatment } \\
\hline & \multicolumn{2}{|c|}{ Disulfiram } & \multicolumn{2}{|c|}{ Placebo } \\
\hline & CT/TT & CC & $\mathrm{CT} / \mathrm{TT}$ & CC \\
\hline$N$ & 14 & 10 & 18 & 14 \\
\hline$\%$ Male & 64 & 70 & 72 & 61 \\
\hline$\%$ Caucasian & 93 & 70 & 89 & 43 \\
\hline$\%$ African American & 0 & 20 & 6 & 43 \\
\hline$\%$ Hispanic & 7 & 10 & 6 & 14 \\
\hline \% Employed & 69 & 80 & 67 & 50 \\
\hline Age years (SD) & $36(8.1)$ & 42 (10.9) & $37(9.1)$ & $43(13.1)$ \\
\hline Cocaine last 30 days (SD) & $15(9.4)$ & $14(10.9)$ & $19(9.2)$ & $21(9.1)$ \\
\hline Cocaine years (SD) & $6(4.8)$ & $13(8.3)$ & $14(9.3)$ & $14(8.5)$ \\
\hline$\%$ Alcohol use & 36 & 40 & 39 & 36 \\
\hline$\%$ Marijuana use & 57 & 50 & 44 & 50 \\
\hline$\%$ Past methadone & 29 & 70 & 56 & 57 \\
\hline
\end{tabular}

No significant baseline differences among the two treatment groups by genotype in any clinical characteristics after adjusting for multiple testing $(p>0.05)$.

When the complete urine toxicology sample $(N=56)$ was compared to total sample $(N=67)$, there were no significant differences between the two samples for any of the demographic variables (Table 1). Additionally, when comparing demographic data for the 11 individuals excluded from analysis to the individuals included in the final analyses $(N=56)$, there were no significant differences for any of the demographic variables $(p \geq 0.1)$.

\section{COCAINE TREATMENT OUTCOMES BY GROUP}

We divided the 67 patients who had been genotyped for the MTHFR rs1801133 variant into two groups based on presence of the $\mathrm{T}$ (minor) allele. For the first analysis, only those individuals with complete urine toxicology for the 12 week study were included $(N=56)$. We first looked at all individuals in the placebo group as compared to the disulfiram group, regardless of genotype. Results showed that individuals in the placebo group did not have a significant reduction in cocaine-positive urines over time (79\% positive at week 1 versus $77 \%$ positive at week 12 ), while individuals in the disulfiram group had a significant reduction in cocaine-positive urines over time $(76 \%$ positive urines at week 1 versus $59 \%$ positive urines at week $12, F=22.38$; $d \mathrm{f}=1,332$; $p<0.0001$, with an effect size of 0.065; see Figure 2).

\section{COCAINE TREATMENT OUTCOMES BY MTHFR GENOTYPE}

The $\mathrm{T}$ allele carrier group, which included individuals with CT or TT MTHFR genotypes, showed better response to disulfiram than did individuals not carrying the rs1801133 minor $\mathrm{T}$ allele ( $F=15.97 ; d \mathrm{f}=1,182 ; p<0.0001$, and an effect size of 0.0806$)$. The CC genotype group showed a more modest, but still significant, difference between disulfiram and placebo $(F=7.27 ; d \mathrm{f}=1$, $134 ; p=0.007$, with an effect size of 0.0514). As shown in Figure 3, cocaine-positive urines for the $\mathrm{T}$ allele patients during the two baseline weeks were approximately $74 \%$ for both disulfiram and 


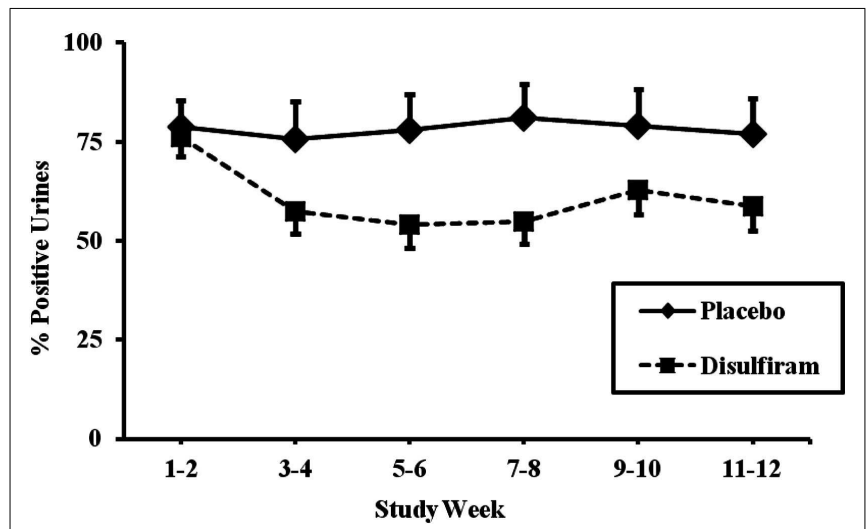

FIGURE 2 | Response to disulfiram therapy by treatment group ( $N=\mathbf{5 6}$ ). Cocaine-positive urine toxicology screens are shown for each 2 week time period across the 12-week trial as percent positive urines. The placebo treatment group $(N=32)$ is represented by a solid line and the disulfiram $(250 \mathrm{mg} /$ day) treatment group $(N=24)$ is represented by a dashed line. Standard error bars are shown for each time point. Only data from study participants with complete urine toxicologies were included in the analysis.

placebo treatment groups. These rates dropped to $52 \%$ during the last 2 weeks of treatment for the disulfiram group and to $71 \%$ for the placebo group $(F=6.982, d \mathrm{f}=1,134, p=0.009$ with an effect size of 0.0495$)$. In comparison, baseline cocaine urines for the CC genotype group were approximately $83 \%$ for disulfiram and placebo treatment groups (see Figure 3). These rates decreased to $69 \%$ during the last 2 weeks for the disulfiram treatment group and were unchanged for the placebo group.

When all individuals were analyzed together, which included those with missing data points, the results were similar. Without regard to genotype, the placebo group had a non-significant reduction in cocaine-positive urines from 80 to $75 \%$, while the disulfiram group had significant reduction in cocaine-positive urines from 79 to $62 \%(F=16.44, d f=1,358$; $p<0.0001)$. When MTHFR rs1801133 genotype was considered in the analysis, the $T$ allele genotype group, again, responded better to disulfiram. The $\mathrm{T}$ allele genotype group dropped from $79 \%$ cocaine-positive urines at baseline to $52 \%$ positive urines at 12 weeks $(F=11.01$; $d \mathrm{f}=1,198 ; p=0.001)$, while the CC genotype group showed a less dramatic reduction from $81 \%$ positive urines to $69 \%(F=6.36$; $d \mathrm{f}=1,154 ; p=0.0127)$.

\section{DISCUSSION}

In this study, we tested the hypothesis that the C677T (rs1801133) variant in MTHFR is associated with response to disulfiram treatment in CD individuals. Our data support the hypothesis that individuals who had at least one copy of the minor MTHFR (T) rs1801133 allele showed better response to disulfiram than those individuals without a $\mathrm{T}$ allele.

The SNP examined in this study, rs1801133 or C677T, is a non-synonymous transition known to alter the enzyme activity of MTHFR. The 677T allele codes for an alanine to valine amino acid change and produces a thermolabile form of the enzyme that has $50-60 \%$ reduced enzyme activity at increased temperatures than
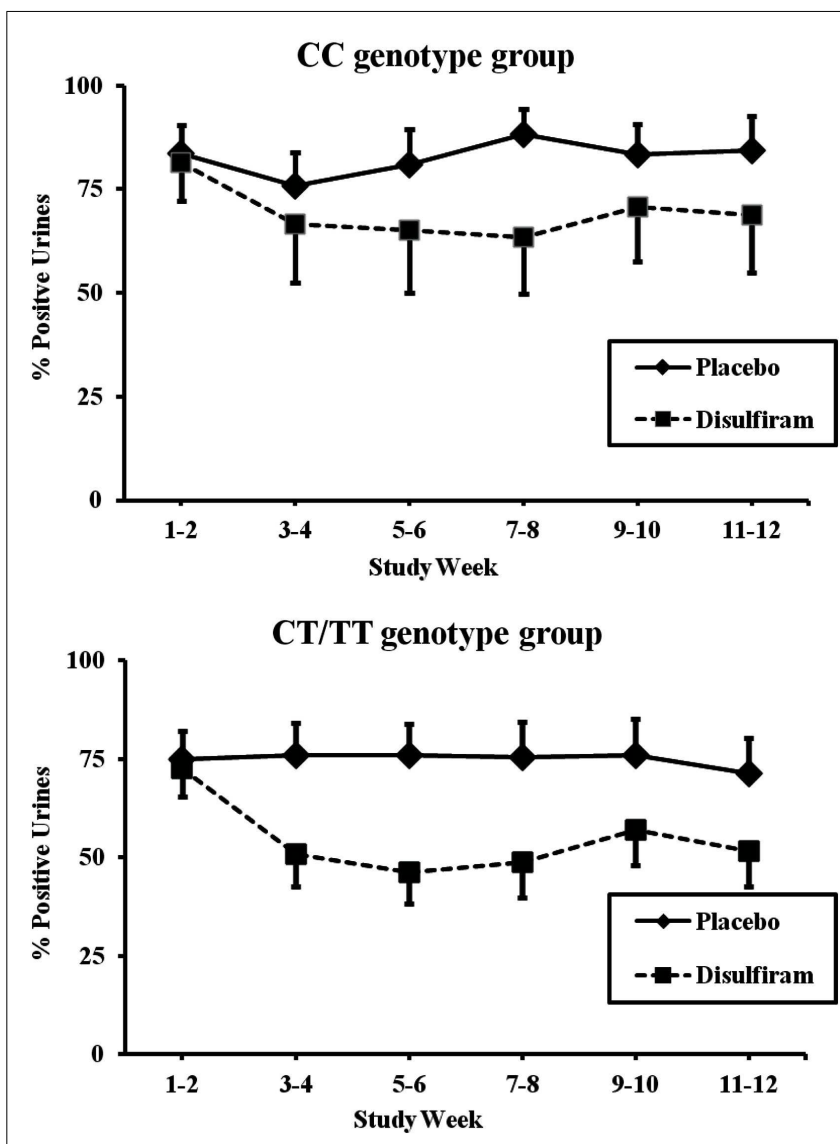

FIGURE 3 | Response of MTHFR C677T CC and CT/TT genotype groups to disulfiram pharmacotherapy in individuals with complete urine toxicology data $(\boldsymbol{N}=\mathbf{5 6})$. Cocaine-positive urine toxicologies are shown for each 2 week time period across the 12-week trial in percent positive urines. The solid line represents time points for the placebo treatment group and the dashed line represents time points for the disulfiram treatment group $(250 \mathrm{mg} /$ day). Top panel: patients with the MTHFR CT/TT or TT genotype (disulfiram, $N=14$; placebo, $N=18$ ). Bottom panel: patients with MTHFR CC genotype (disulfiram, $N=10$; placebo, $N=14$ ). Standard error bars are shown for each time point.

the protein resulting from the allele with the more common $677 \mathrm{C}$ variant (Frosst et al., 1995). As mentioned previously, MTHFR is a key component of the folic acid metabolic cycle, and is therefore central to maintaining the balance of folic acid (folate, pteroylglutamic acid) to homocysteine in the body. Typically an inverse relationship exists; as folate increases, homocysteine decreases. Higher systemic levels of homocysteine (i.e., lower levels of folate) correlate with decreased cognitive function, and are associated with white matter lesions in the brain (de Lau et al., 2007, 2009). Higher systemic levels of folate (i.e., lower levels of homocysteine) have been found to be associated with increased cognitive function (Morris et al., 2001; Malouf and Grimley Evans, 2008; Moretti et al., 2008; Sen and Kanani, 2009; Tangney et al., 2009). For example, increased folate levels in elderly individuals were found to be associated with slower cognitive decline, while increased homocysteine levels were associated with faster cognitive decline (Tangney et al., 2009). Another study illustrated that elderly individuals who 
took folic acid supplements daily showed significant improvement in global cognitive functioning (Malouf and Grimley Evans, 2008) and a similar effect was observed in school-aged girls supplemented with both folate and iron (Sen and Kanani, 2009). Likewise, folate deficiency in the CNS causes cognitive deficits such as dyskinesia, psychomotor retardation, intellectual delay (Moretti et al., 2008), and low folate levels were found to be associated with reduced memory function (Morris et al., 2001).

5,10-Methylene tetrahydrofolate reductase is known to be a critical player in the development of the CNS in humans. Low folate levels are associated with increased incidence of NTDs (van der Linden et al., 2006; Greene et al., 2009; Harris, 2009), a medical condition in which the neural tube, the developmental precursor to the CNS, does not close fully and leaves neural tissue open to the environment. Folic acid supplementation was so successful in reducing the occurrence and recurrence of NTDs that mandatory folate fortification of grain products was initiated by the FDA in 1998 (MRC Vitamin Study Research Group, 1991; Czeizel and Dudas, 1992; Food and Drug Administration, 1996; Berry et al., 1999).

Individuals homozygous for the low activity $\mathrm{T}$ allele of MTHFR have higher overall plasma levels of homocysteine (Jacques et al., 1996; Rozen, 1997; Yang et al., 2008). The 677T variant has been associated with various psychological conditions including depression and/or loneliness, and with attention deficit hyperactivity disorder in specific patient populations (Hickie et al., 2001; Krull et al., 2008; Holmes et al., 2011; Kamdar et al., 2011; Lan et al., 2012).

Because MTHFR and folic acid metabolism are important for providing metabolites for methylation, and because disulfiram and cocaine can both affect DNA and/or histone methylation levels, the pharmacogenetic effect in disulfiram treatment for CD may be related to the interaction of these epigenetic effects. The $\mathrm{T}$ allele of MTHFR variant rs 1801133 has been found to be associated with higher homocysteine levels (Jacques et al., 1996; Rozen, 1997; Yang et al., 2008), and increased homocysteine levels (and its metabolites) have been found to be associated with global DNA hypomethylation (Yi et al., 2000; Caudill et al., 2001). In addition, hypomethylation was observed in women carrying one minor $\mathrm{T}$ allele in conjunction with folate deficiency, and in women carrying two minor T alleles of MTHFR rs1801133 in the presence of vitamin B6 deficiency (Axume et al., 2007; La Merrill et al., 2012). Similarly, mice with one or both copies of MTHFR knocked out showed hyperhomocysteinemia as well as global DNA hypomethylation (Chen et al., 2001). Cocaine itself can affect epigenetics either at the DNA or histone level. For example, acute cocaine administration in mice increases local methylation of specific genes via upregulating DNA methyltransferases in the brain (Anier et al., 2010). In contrast, chronic cocaine administration or use decreased $\mathrm{H} 3 \mathrm{~K} 9$ histone methylation (Maze et al., 2010; Covington et al., 2011),

\section{REFERENCES}

Anier, K., Malinovskaja, K., AonurmHelm, A., Zharkovsky, A., and Kalda, A. (2010). DNA methylation regulates cocaine-induced behavioral sensitization in mice. Neuropsychopharmacology 35, 2450-2461.
Axume, J., Smith, S., Pogribny, I., Moriarty, D., and Caudill, M. (2007). The MTHFR 677TT genotype and folate intake interact to lower global leukocyte $\mathrm{DNa}$ methylation in young Mexican American women. Nutr. Res. 27, 1365-1317.

decreased global DNA methylation (in offspring of mice who had been administered chronic cocaine; Novikova et al., 2008), and decreased heterochromatinization (Maze et al., 2011). Disulfiram also can affect the epigenetic landscape by decreasing global DNA methylation (Lin et al., 2011). Methylation is an important process by which gene expression is mediated, and may be the basis of the genetic effect observed in disulfiram treatment for CD and MTHFR genotype. Additional research is required to test this hypothesis and to further elucidate the specific underpinnings of the effect of MTHFR alleles on CD pharmacotherapies such as disulfiram.

We have recently published two studies showing associations between response to disulfiram with the genes coding for dopamine- $\beta$ hydroxylase ( $D \beta H$; Kosten et al., 2012), the serotonin transporter (5-HTTLPR), and tryptophan hydroxylase two (TPH2; Nielsen et al., 2012b). These studies also illustrated a pharmacogenetic effect in disulfiram therapy. Specifically, the first study found that the group homozygous for the major $\mathrm{C}$ allele of $D \beta H$ showed a treatment response with disulfiram (e.g., decreased cocaine-positive urines over the 12-week trial), while the minor $\mathrm{T}$ allele, which associates with lower $\mathrm{D} \beta \mathrm{H}$ levels, did not. Nielsen et al. (2012b), showed that subjects with at least one copy of the minor allele of 5-HTTLPR or TPH2, or both, responded to disulfiram therapy, while the genotype groups with the major alleles of both genes did not show reduced cocaine-positive urines (Nielsen et al., 2012a). With the addition of the new findings in this study, that the C677T variant in the folate metabolism gene MTHFR is a potential modifying factor in disulfiram pharmacotherapy for cocaine dependence, we propose that the genetic profile of an individual including findings such as these may be used to help in tailoring a more effective pharmacotherapy for CD.

In conclusion, this study identifies the C677T variant in the folate metabolism gene, MTHFR, as a potential modifying factor in disulfiram pharmacotherapy for cocaine dependence. Specifically, individuals carrying the minor $\mathrm{T}$ allele showed increased response to disulfiram treatment. This finding may be useful in tailoring treatment for $\mathrm{CD}$ to an individual based on genotype, thereby increasing the efficacy of CD pharmacotherapy. However, this is a clinical trial with a small cohort therefore replication studies will be required to confirm these results.

\section{ACKNOWLEDGMENTS}

We thank J. Lappalainen and G. Wu for recruitment, screening, and assessment of subjects. This study was supported by NIH/NIDA 5 P50 DA018197-05 (T. R. Kosten), the Veterans Health Administration, and the Toomim Family Fund. The authors report no potential conflicts of interest. This material is the result of work supported with resources and the use of facilities at the Michael E. DeBakey VA Medical Center, Houston, TX.

Berke, J., Paletzki, R., Aronson, G., Hyman, S., and Gerfen, C. (1998). A complex program of striatal gene expression induced by dopaminergic stimulation. J. Neurosci. 18, 5301-5310.

Berrettini, W., Hoehe, M., Ferraro, T., Demaria, P., and Gottheil, E. (1997).
Human mu opioid receptor gene polymorphisms and vulnerability to substance abuse. Addict. Biol. 2, 303-308.

Berry, R., Erickson, J., Moore, C., Wang, H., Mulinare, J., Zhao, P., et al. (1999). Prevention of neural-tube defects with folic acid in China. 
China-U.S. Collaborative project for neural tube defect prevention. $N$. Engl. J. Med. 341, 1485-1490.

Carroll, K. M. (1993). Psychotherapeutic treatment of cocaine abuse: models for its evaluation alone and in combination with pharmacotherapy. NIDA Res. Monogr. 135, 116-132.

Carroll, K. M. (1997). Manual-guided psychosocial treatment. A new virtual requirement for pharmacotherapy trials? Arch. Gen. Psychiatry 54, 923-928.

Carroll, K. M., Fenton, L. R., Ball, S. A., Nich, C., Frankforter, T. L., Shi, J., et al. (2004). Efficacy of disulfiram and cognitive behavior therapy in cocaine-dependent outpatients: a randomized placebocontrolled trial. Arch. Gen. Psychiatry 61, 264-272.

Carroll, K. M., Nich, C., Ball, S. A., McCance, E., and Rounsavile, B. J. (1998). Treatment of cocaine and alcohol dependence with psychotherapy and disulfiram. Addiction 93, 713-727.

Caudill, M., Wang, J., Melnyk, S., Pogribny, I., Jernigan, S., Collins, M., et al. (2001). Intracellular $S$-adenosylhomocysteine concentrations predict global DNA hypomethylation in tissues of methyl-deficie3nt cystathionine beta-synthase heterozygous mice. J. Nutr. 131, 2811-2818.

Chen, Z., Karaplis, A., Ackerman, S., Pogribny, I., Melnyk, S., LussierCacan, S., et al. (2001). Mice deficient in methylenetetrahydrofolate reductase exhibit hyperhomocysteinemia and decreased methylation capacity, with neuropathology and aortic lipid deposition. Hum. Mol. Genet. 10, 433-443.

Covington, H., Maze, I., Sun, H., Bomze, H., Demaio, K., Wu, E., et al. (2011). A role for repressive histone methylation in cocaine-induced vulnerability to stress. Neuron 71, 656-670.

Crist, R., Ambrose-Lanci, L., Vaswani, M., Clarke, T., Zeng, A., Yuan, C., et al. (2012). Case-control association analysis of polymorphisms in the delta-opioid receptor, OPRD1, with cocaine and opiod addicted populations. Drug Alcohol Depend. [epub ahead of print].

Czeizel, A., and Dudas, I. (1992). Prevention of the first occurance of neural-tube defects by periconceptional vitamin supplementation. $N$. Engl. J. Med. 327, 1832-1835.

Dahl, J., Kampman, K., Oslin, D., Weller, A., Lohoff, F., Ferraro, T., et al. (2005). Association of a polymorphism in the Homerl gene with cocaine dependence in an African American population. Psychiatr. Genet. 15, 277-283.

de Lau, L., Refsum, H., Smith, A., Johnson, C., and Breteler, M. (2007). Plasma folate concentration and cognitive performance: Rotterdam scan study. Am. J. Clin. Nutr. 86, 728-734.

de Lau, L., Smith, A., Refsum, H., Johnson, C., and Breteler, M. (2009). Plasma vitamin B12 status and cerebral white-matter lesions. J. Neurol. Neurosurg. Psychiatry 80, 149-157.

Food and Drug Administration. (1996). Food standards: amendment of standards of identity for enriched grain products to require addition of folic acid. Final rule, 21 CFR parts 136,137 and 139. The Federal Register 61, 8781-8797.

Frosst, P., Blom, H., Milos, R., Govette, P., Sheppard, C., Matthews, R., et al. (1995). A candidate genetic risk factor for vascular disease: a common mutation in methylenetetrahydrofolate reductase. Nat. Genet. 10, 111-113.

George, T. P., Chawarski, M. C., Pakes, J., Carroll, K. M., Kosten, T. R., and Schottenfeld, R. S. (2000). Disulfiram versus placebo for cocaine dependence in buprenorphinemaintained subjects: a preliminary trial. Biol. Psychiatry 47, 1080-1086.

Goldman, D., Oroszi, G., and Ducci, F. (2005). The genetics of addictions: uncovering the genes. Nat. Rev. Genet. 6, 521-532.

Greene, N., Stanier, P., and Copp, A. (2009). Genetics of human neural tube defects. Hum. Mol. Genet. 18, R113-R129.

Grimm, J., Lu, L., Hayashi, T., Hope, B., Su, T., and Shaham, Y. (2003). Time-dependent increases in brainderived neurotrophic factor protein levels within the mesolimbic dopamine system after withdrawal from cocaine: implications for incubation of cocaine craving. J. Neurosci. 23, 742-747.

Harisha, P., Devi, B., Christopher, R., and Kruthika-Vinod, T. (2010). Impace of 5,10methylenetetrahydrofolate reductase gene polymorphism on neural tube defects. J. Neurosurg. Pediatr. 6, 364-367.

Harris, M. (2009). Insights into prevention of human neural tube defects by folic acid arising from consideration of mouse mutants. Birth Defects Res. A Clin. Mol. Teratol. 85, 331-339.

Hickie, I., Scott, E., Naismith, S., Ward, P., Turner, K., Parker, G., et al. (2001). Late-onset depression: genetic, vascular and clinical contributions. Psychol. Med. 31, 1403-1412.

Holmes, M., Newcombe, P., Hubacek, J., Sofat, R., Ricketts, S., Cooper, J., et al. (2011). Effect modification by population dietary folate on the association between MTHFR genotype, homocysteine, and stroke risk: a meta-analysis of genetic studies and randomised trials. Lancet 378, 584-594.

Hubisz, M. J., Falush, D., Stephens, M., and Pritchard, J. K. (2009). Inferring weak population structure with the assistance of sample group information. Mol. Ecol. Resour. 9, 1322-1332.

Jacques, P., Bostom, A., Williams, R. Ellison, R., Eckfeldt, J., Rosenberg, I., et al. (1996). Relation between folate status, a common mutation in methylenetetrahydrofolate reductase, and plasma homocysteine concentrations. Circulation 93, 7-9.

Kalivas, P., and O'Brien, C. (2008). Drug addiction as a pathology of staged neuroplasticity. Neuropsychopharmacology 33, 166-180.

Kamdar, D., Krull, K., El-Zein, R. Brouwers, P., Potter, B., Harris, L., et al. (2011). Folate pathway polymorphisms predict deficits in attention and processing speed after childhood leukemia therapy. Pediatr. Blood Cancer 57, 454-460.

Kendler, D., and Prescott, C. (1998). Cocaine use, abuse and dependence in a population-based sample of female twins. Br. J. Psychiatry 173, 345-350.

Kinney, S., and Pradhan, S. (2011). Regulation of expression and activity of DNA (cytosine-5) methyltransferases in mammalian cells. Prog. Mol. Biol. Transl. Sci. 101, 311-333.

Kosten, T., Wu, G., Huang, W., Harding, M., Hamon, S., Lappalainen, J., et al. (2012). Pharmacogenetic randomized trial for cocaine abuse: disulfiram and dopamine betahydroxylase. (in press).

Kreek, M., Bart, G., Lilly, C., Laforge, K., and Nielsen, D. (2005). Pharmacogenetics and human molecular genetics of opiate and cocaine addictions and their treatments. Pharmacol. Rev. 57, 1-26.

Krull, K., Brouwers, M., Jain, N., Zhang, L., Bomgaars, L., Dreyer, Z., et al. (2008). Folate pathway genetic polymorphisms are related to attention disorders in childhood leukemia survivors. J. Pediatr. 152, 101-105.

La Merrill, M., Torres-Sanchez, L., Ruiz-Ramos, R., Lopez-Carillo, L., Cebrian, M., and Chen, J. (2012). The association between first trimester micronutrient intake, MTHFR genotypes, and global DNA methylation in pregnant women. $J$. Matern. Fetal. Neonatal. Med. 25, 133-137.

Lan, W., Yang, A., Hwang, J., Hong, C., Liou, Y., Yeh, H., et al. (2012). Association of MTHFR C677T polymorphism with loneliness but not depression in cognitively normal elderly males. Neurosci. Lett. 521, 88-91.

Lao, O., Dujin, K. V., Kersbergen, P., Knijff, P. D., and Kayser, M. (2006). Proportioning whole-genome singlenucleotide-polymorphism diversity for the identification of geographic population structure and genetic ancestry. Am. J. Hum. Genet. 78, 680-690.

Lin, J., Haffner, M., Zhang, Y., Lee, B., Brennen, W., Britton, J., et al. (2011). Disulfiram is a DNA demethylating agent and inhibits prostate cancer cell growth. Prostate 71, 333-343.

Malouf, R., and Grimley Evans, J. (2008). Folic acid with or without vitamin B12 for the prevention and treatment of healthy elderly and demented people. Cochrane Database Syst. Rev. 8, CD004514.

Maze, I., Covington, H., Dietz, D., Laplant, Q., Renthal, W., Russo, S., et al. (2010). Essential role of the histone methyltransferase G9a in cocaine-induced plasticity. Science 327, 213.

Maze, I., Feng, J., Wilkinson, M., Sun, H., Shen, L., and Nestler, E. (2011) Cocaine dynamically regulates heterochromatin and repetitive element unsilencing in nucleus accumbens. Proc. Natl. Acad. Sci. U.S.A. 108, 3035-3040.

McLellan, A., Kushner, H., Metzger, D., Peters, R., Grissom, G., Pettinati, H., et al. (1992). The fifth edition of the addiction severity index. J. Subst. Abuse Treat. 9, 199-213.

Moretti, P., Peters, S., Del Gaudio, D., Sahoo, T., Hyland, K., Bottiglieri, T., et al. (2008). Brief report: autistic symptoms, developmental regression, mental retardation, epilepsy, and diskinesias in CNS folate deficiency. J. Autism Dev. Disord. 38, 1170-1177.

Morris, M., Jacques, P., Rosenberg, I., and Selhub, J. (2001). Hyperhomocysteinemia associated with poor recall in the third National Health and Nutrition Examination Survey. Am. J. Clin. Nutr. 73 , 927-933.

MRC Vitamin Study Research Group. (1991). Prevention of neural tube defects: results of the Medical Research Council Vitamin Study. Lancet 338, 131-137. 
Nestler, E. (2001). Molecular basis of long-term plasticity underlying addiction. Nat. Rev. Neurosci. 2, 119-128.

Nielsen, D., Hamon, S., Yuferov, V., Jackson, C., Ho, A., Ott, J., et al. (2010). Ethnic diversity of DNA methylation in the OPRM1 promoter region in lymphocytes of heroin addicts. Hum. Genet. 127, 639-649.

Nielsen, D., Yuferov, V., Hamon, S., Jackson, C., Ho, A., Ott, J., et al. (2009). Increased OPRM1 DNA methylation in lymphocytes of methadone-maintained former heroin addicts. Neuropsychopharmacology 34, 867-873.

Nielsen, D. A., Harding, M. J., Hamon, S., Huang, W., and Kosten, T. (2012a). Modifying role of serotonergic 5-HTTLPR \& TPH2 variants on disulfiram treatment of cocaine addiction: a preliminary study. Gene. Brain Behav. (in press).

Nielsen, D. A., Utrankar, A., Reyes, J., Simons, D., and Kosten, T. (2012b). Epigenetics of drug abuse: predisposition or response. Pharmacogenomics 13, 1149-1160.

Novikova, S., He, F., Bai, J., Cutrufello, N., Lidow, M., and Undieh, A. (2008). Maternal cocaine administration in mice alters DNA methylation and gene expression in hippocampal neurons of neonatal and prepubertal offspring. PLOS ONE 3:e1919. doi:10.1371/journal.pone.0001919

Petrakis, I. L., Carroll, K. M., Nich, C., Gordon, L. T., McCanceKatz, E. F., Frankforter, T., et al. (2000). Disulfiram treatment for cocaine dependence in methadone-maintained opioid addicts. Addiction 95, 219-228.

Pritchard, J. K., Stephens, M., and Donnelly, P. (2000). Inference of population structure using multilocus genotype data. Genetics 155, 945-959.

R Development Core Team. (2009). R: A Language and Environment for Statistical Computing, 2.9.1 Edn, Vienna: R Foundation for Statistical Computing.

Rozen, R. (1997). Genetic predisposition to hyperhomocysteinemia: deficiency of methylenetetrahydrofolate reductase (MTHFR). Thromb. Haemost. 78, 523-526.

Sen, A., and Kanani, S. (2009). Impact of iron-folic acid supplementation on cognitive abilities of school girls in Vadodara. Indian Pediatr. 46, 849-854.

Shaham, Y., and Hope, B. (2005). The role of neuroadaptations in relapse to drug seeking. Nat. Neurosci. 8, 1437-1439.

Sheehan, D., Lecrubier, Y., Sheehan, K., Amorim, P., Janavs, J., Weiller, E., et al. (1998). The MiniInternational Neuropsychiatric Interview (M.I.N.I.): the development and validation of a structured diagnostic psychiatric interview for DSM-IV and ICD-10. J. Clin. Psychiatry 59, 22-33.

Substance Abuse and Mental Health Services Administration (SAMHSA). (2011). Results from the 2010 National Survey on Drug Use and Health: Summary of National Findings. NSDUH Series H-41, HHS Publication No. (SMA) 11-4658. Rockville: Substance
Abuse and Mental Health Services Administration.

Tangney, C., Tang, Y., Evans, D., and Morris, M. (2009). Biochemical indicators of vitamin B12 and folate insufficiency and cognitive decline. Neurology 72, 361-367.

Tsuang, M., Lyons, M., Meyer, M., Doyle, T., Eisen, S., Goldberg, J., et al. (1998). Co-occurrence of abuse of different drugs in men: the role of drug-specific and shared vulnerabilities. Arch. Gen. Psychiatry 55, 967-972.

van der Linden, I., Afman, L., Heil, S., and Blom, H. (2006). Genetic variation in genes of folate metabolism and neural-tube defect risk. Proc. Nutr. Soc. 65, 204-215.

Whitehead, A., Gallagher, P., Mills, J., Kirke, P., Burke, H., Molloy, A., et al. (1995). A genetic defect in 5,10 methylenetetrahydrofolate reductase in neural tube defects. QJM 88, 763-766.

Wong, C., Mill, J., and Fernandes, C. (2011). Drugs and addiction: an introduction to epigenetics. Addiction 106, 480-489.

Yang, Q., Botto, L., Gallagher, M. Friedman, J., Sanders, C., Koontz, D., et al. (2008). Prevalence and effects of gene-gene nutrient interactions on serum folate and serum total homocysteine concentrations in the United States: findings from the third National Health and Nutrition Examination Survey DNA Bank. Am. J. Clin. Nutr. 88, 232-246.

Yao, W., Gainetdinov, R., Arbuckle, M., Sotnikova, T., Cyr, M., Beaulieu, J., et al. (2004). Identification of PSD95 as a regulator of dopaminemediated synaptic and behavioral plasticity. Neuron 41, 625-638.

Yi, P., Melnyk, S., Pogribna, M., Pigribny, I., Hine, R., and James, S. (2000). Increase in plasma homocysteine associated with increases in plasma S-adenosylhomocysteine and lymphocyte DNA hypomethylation. J. Biol. Chem. 275, 29318-29323.

Conflict of Interest Statement: The authors declare that the research was conducted in the absence of any commercial or financial relationships that could be construed as a potential conflict of interest.

Received: 24 August 2012; accepted: 01 December 2012; published online: 14 January 2013.

Citation: Spellicy CJ, Kosten TR, Hamon SC, Harding MJ and Nielsen DA (2013)

The MTHFR C677T variant is associated with responsiveness to disulfiram treatment for cocaine dependency. Front. Psychiatry 3:109. doi: 10.3389/fpsyt.2012.00109

This article was submitted to Frontiers in Addictive Disorders and Behavioral Dyscontrol, a specialty of Frontiers in Psychiatry.

Copyright (c) 2013 Spellicy, Kosten, Hamon, Harding and Nielsen. This is an open-access article distributed under the terms of the Creative Commons Attribution License, which permits use, distribution and reproduction in other forums, provided the original authors and source are credited and subject to any copyright notices concerning any third-party graphics etc. 